\title{
Inhalations of 5-ALA in photodynamic diagnosis of bronchial cancer
}

\author{
W.J. Piotrowski1,2, J. Marczak1,2, A. Nawrocka33, A. Antczak1,2, P. Górski2
}

ABSTRACT: Inhalations of 5-ALA in photodynamic diagnosis of bronchial cancer. W.J. Piotrowski, J. Marczak, A. Nawrocka, A. Antczak, P. Górski.

Background: Photodynamic bronchoscopy (PDD) allows for early detection of bronchial cancer. Adverse effects and high costs, partly related to general application of photosensitisers, are important limitations of the method. The local application of a photosensitiser could help to minimize these problems. In this study the validity and safety of inhaled 5-ALA have been tested.

Methods: We examined 49 patients (age 59 \pm 11 , cigarette consumption $36 \pm 17$ pack-years) with present or past respiratory neoplasms and other with increased risk of bronchial cancer by photodynamic bronchoscopy (StorzD-light) after inhaled 5-ALA. Biopsies were taken from the fluorescence-positive and negative foci (control). Symptoms and pre-/post-inhalation spirometry were analysed.

Results: The overall sensitivity was $82 \%$, specificity $62 \%$, positive predicted value (PPV) $45 \%$ and negative predictive value (NPV) $90 \%$. Specificity decreased to $53 \%$ and PPV to $15 \%$ when visible tumours were excluded. PDD, when added to white light bronchoscopy increased sensitivity by $2.1 \%$ and NPV by $6 \%$, but decreased specificity by $35.4 \%$ and PPV by $53.1 \%$. In a group of actual or past tumours the sensitivity increased by $22 \%$ and NPV by $34 \%$, whereas specificity decreased by $26 \%$ and PPV by $35 \%$. In 2 cases a drop in $\mathrm{FEV}_{1}$ above $10 \%$ of pre-inhalation value was observed but no clinically relevant symptoms were reported.

Conclusions: Photodynamic bronchoscopy with inhalation of 5-ALA is a relatively safe diagnostic method. The main disadvantage is high percentage of false positive results. Nevertheless, we believe, that it may be a useful adjunct to conventional diagnostic modes, especially in the detection of early lesions in patients operated due to cancer (stump control and detection of metachronous lesions) and those prepared for operation (synchronous lesions and detection of infiltration margins). However all suspected lesions must be verified by histo-pathological examination.

Monaldi Arch Chest Dis 2004; 61: 2, 86-93.

Keywords: Photodynamic bronchoscopy, bronchial cancer, early detection, photosensitiser.

1 Department of Pneumology and Allergology, Medical University of Lodz, Poland.

2 Centre of Laser Diagnosis and Therapy, Technical University of Lodz, Poland.

3 Department of Pathology, Medical University of Lodz, Poland.

Correspondence: Pawel Górski MD, PhD, Department of Pneumology and Allergology, Medical University of Lodz, Kopciskiego 22, 90-153 Lodz, Poland; e-mail; pgorski@ pdi.net

The study was supported by Polish State Committee for Scientific Research (PBZ/KBN/004/CD/T-11/2000).

\section{Introduction}

Bronchial cancer is spreading worldwide and has become one of most frequent neoplasms, both in men and women. Late diagnosis is common. In most cases the treatment of choice is surgery, but only $10 \%$ of patients can be treated this way when the cancer is recognised. The screening programmes based on sputum cytology or periodic Xray examinations implied so far have been proved unsatisfactory [1]. Conventional white light bronchoscopy (WLB) is very useful in detecting endobronchial tumours, but its value in recognising early neoplastic or pre-neoplastic lesions is low. Fluorescent bronchoscopy is a relatively new method based on a photobiological effect, namely the ability of porphyrins and other natural stains to emit red light, when exposed to a violet light. It has been shown, that the relative sensitivity of WLB combined with autofluorescence (LIFE, Xillix) vs. WLB alone was 2.71 for all types of lesions (pre- neoplastic, intraepithelial carcinoma and invasive carcinoma) [2]. Neoplastic cells accumulate porphyrins in an almost selective manner. There is an assumption, that the signal may be enhanced by application of porphyrin derivatives from external sources, but the comparative studies between autofluorescence and sensitiser-enhanced photodynamic bronchoscopy (PDD) are not available. Unfortunately, the risk of adverse events occurs, mainly skin toxicity due to UV-light (sun burns or periorbital edema). The photosensitisers, such as haematoporphyrin derivatives $(\mathrm{HpD})$ or 5 -aminolevulinic acid (5-ALA), a precursor of protoporphyrin IX (PpIX), are usually applied intravenously or orally. Sensitised neoplastic tissue may be treated further with non-thermal, low energy laser irradiation (photodynamic treatment-PDT), both for radical and palliative effects. Both, cost and safety may be reduced by the use of local application of photosensitisers. It has been proved to be efficient in photodynamic detection of urinary bladder [3], skin ma- 
lignancy [4], or laryngeal and oropharyngeal tumours $[5,6]$. Inhalations of 5-ALA have been used to detect early stage lung cancer and shown to be safe and reliable [7]. Unfortunately, the cited study included only seven patients. Since the cited trial no further data on application of inhaled photosensitisers for detection of endobronchial lesions have been published. Therefore, we wanted to evaluate whether this method of visualisation is effective in diagnosis of bronchial neoplasms and whether inhalations of 5-ALA are safe.

\section{Materials and methods}

Patients. Photodynamic bronchoscopy was performed in 72 patients. From this group 49 patients were selected for the analysis. The remaining patients were disregarded as not-fitting to study groups or due to incomplete data and histopathological examinations. Selected patients were divided into four groups: Patients with laryngo-tracheo-bronchial tumors diagnosed by conventional diagnostic modes $(n=17)$, consisted of 7 non-small cell lung carcinomas - NSCLC (6 squamous, 1 undefined), 4 small cell lung carcinomas, 5 undefined lung tumours and 1 squamous cell laryngeal cancer; patients previously operated due to bronchial tumours $(n=6)$, with a history of squamous cell lung carcinoma $(n=4)$ and adenocarcinoma $(n=2)$; patients operated on laryngeal cancer $(n=4)$; and present or ex-heavy smokers without signs of tumour in conventional examinations $(\mathrm{n}=22)$. Table 1 shows study population. All patients signed written informed consent, which included both the consent for bronchoscopy and inhalation of 5-ALA. The local Ethics Committee at Medical University of Lodz accepted the protocol.

Inhalations. 5-ALA ( $\delta$-aminolevulinic acid) was purchased from Medac Gmbh (Hamburg, Germany). The 5\% solution was prepared according to Baumgartner et al. [7], with the substitution of $2.1 \%$ $\mathrm{NaHCO}_{3}$ in $\mathrm{H}_{2} \mathrm{O}$, instead of $0.9 \% \mathrm{NaCl}$. The reason for this change was low $\mathrm{pH}$ of 5-ALA saline solution

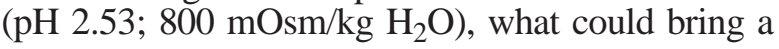

risk of serious bronchospasm in some patients. The chosen solution had pH 5.19 and $800 \mathrm{mOsm} / \mathrm{kg}$ $\mathrm{H}_{2} \mathrm{O}$. It was nebulized through a commercially available nebulizer (Airlife Misty-Neb Nebulizer, Allegiance, Mexico) connected to oxygen source. Patients inhaled either $5(n=35)$ or $10 \mathrm{ml}(n=14)$ of ALA solution 3 hours before the bronchoscopic examination. The flow was set up at $0.2 \mathrm{ml} \mathrm{x} \mathrm{min}^{-1}$. The droplet size was not measured for the purpose of this study. Baumgartner et al. [7], who described the original method estimated the mass mean aerodynamic diameter as $5.2 \pm 0.1 \mu \mathrm{m}$ with geometrical standard deviation $2.0 \pm 0.1 \mu \mathrm{m}$. The distribution of white light bronchoscopy (WLB) - visible tumors, resected tumours, patients after laryngectomy and heavy smokers was not different between groups inhaling $5 \mathrm{ml}$ and $10 \mathrm{ml}$ 5-ALA.

Safety evaluation. All patients were asked about symptoms and a physical examination was performed directly before and within 15 minutes after the inhalation in all patients. In 23 patients the spirometry was performed within 15 minutes before and after 5-ALA inhalation.

Bronchoscopy and fluorescence imaging. The examination was performed through the fiberoptic endoscope (Karl Storz, Tuttlingen, Germany), following standards of British Thoracic Society [8]. For fluorescence excitation, a xenon short arc lamp equipped with a special filter system was used (Dlight, Storz). To allow fluorescence imaging, most of the remitted excitation was blocked by the integrated filter of the endoscope (long pass $=440$ $\mathrm{nm})$. A switch allowed a change between white light and fluorescence excitation $\left(\lambda_{\mathrm{ex}}=375-440\right.$ $\mathrm{nm}$ ), thus conventional and PDD examinations could be performed at the same time, however it was a rule, that first evaluation was done in whitelight. Video images were obtained by using a highresolution colour charge coupled device (CCD) camera (Telecam SL PAL, Storz) and findings were recorded on videotape.

Biopsies. The material for pathological examination was taken preferably by forceps. In some cases the brush cytology was performed. The biop-

Table 1. - Patients' characteristics, including age, cigarette consumption, Tiffenau index (FEV $\left.\%_{1} V_{C}\right)$ and $F E V_{1}$ (\% predicted). Lowest and highest value and mean \pm SD are given for each variable

\begin{tabular}{lccccc}
\hline GROUP & $\begin{array}{c}\text { NUMBER } \\
\text { of patients }\end{array}$ & $\begin{array}{c}\text { AGE } \\
\text { (years) }\end{array}$ & $\begin{array}{c}\text { CIGARETTE CONSUMPTION } \\
\text { (pack-years) }\end{array}$ & FEV $_{\mathbf{1}}$ \% VC & $\begin{array}{c}\text { FEV }_{\mathbf{1}} \\
\text { predicted }\end{array}$ \\
\hline TUMOURS & 17 & $42-79$ & $0-100$ & $47-91$ & $43-91$ \\
& & $44 \pm 9$ & $42 \pm 23$ & $71 \pm 12$ & $66 \pm 18$ \\
\hline OPERATED DUE TO & 6 & $44-73$ & $36-40$ & $49-82$ & $54-90$ \\
LUNG TUMOURS & & $64 \pm 11$ & $38 \pm 3$ & $66 \pm 13$ & $61 \pm 7$ \\
\hline POST-LARYNGECTOMY & 4 & $52-66$ & $19-49$ & ND & ND \\
& & $60 \pm 6$ & $38 \pm 16$ & $48-97$ & $40-125$ \\
HEAVY SMOKERS & 22 & $37-75$ & $20-45$ & $77 \pm 17$ & $82 \pm 25$ \\
\hline TOTAL & & $54 \pm 11$ & $31 \pm 9$ & $73 \pm 15$ & $72 \pm 21$ \\
\hline
\end{tabular}


sies were taken from sites indicated by fluorescence imaging and from control sites with no fluorescence (opposite lung, usually upper lobe carina). In tumours visible in white light but not with fluorescence, the biopsy was guided by white light. Such cases were qualified as false negative. Samples were described according to the Saccommano criteria (normal tissue; non-specific inflammation; hyperplasia; metaplasia; mild, moderate and severe dysplasia; carcinoma in situ; invasive carcinoma). The samples were blinded and examined by two independent pathologists. The total number of 62 sites were biopsied (31 from PDD-positive sites), at least 3 biopsies were taken from one site.

Statistical analysis. All numerical data was presented as mean \pm standard deviation. Sensitivity, specificity, positive predictive value (PPV) and negative predictive value (NPV) were calculated using the following formulas:

Sensitivity:

(True-positive/true-positive + false-negative) x 100 Specificity:

(True-negative/true-negative + false-positive) x 100 PPV:

(True-positive/true-positive + false positive) x 100 NPV:

(True-negative/true-negative + false-negative) x 100
True-positive results were defined as positive at fluorescence examination (PDD-positive) and positive by pathological examination (dysplasia, CIS, invasive carcinoma); true-negative results as PDD-negative and negative by pathological examination (normal, non-specific inflammation, metaplasia); false-negative as PDD-negative but positive on pathology; false-positive as PDD-positive but negative on pathological examination.

We used student's T-test for paired samples for estimation of statistical significance between preand post-inhalation spirometry values, and Chisquire test for estimation of differences in distribution of patient's types and true/false, positive/ negative values between patients receiving 5 and $10 \mathrm{ml}$ of 5-ALA. The $\mathrm{p}$ value $\leq 0.05$ was considered significant.

\section{Results}

Validation of $P D D$ in detection of pre-malignant and malignant lesions. The distribution of pathological findings is shown in table 2 and 3. Based on these results, the sensitivity, specificity, PPV and NPV were calculated for the following groups:

1. All patients and all preneoplastic/neoplastic lesions (including WLB-visible tumours). More-

Table 2. - The distribution of pathological findings within groups. At the bottom total number of true positive, true negative, false negative, false positive in patients who inhaled 5 and $10 \mathrm{ml} 5$-ALA. In brackets the percentage of all biopsies taken in each group. No statistically significant differences were observed between 5 and $10 \mathrm{ml}$ group

\begin{tabular}{|c|c|c|c|c|}
\hline GROUP & $\begin{array}{l}\text { TRUE } \\
\text { POSITIVE }\end{array}$ & $\begin{array}{l}\text { TRUE } \\
\text { NEGATIVE }\end{array}$ & $\begin{array}{l}\text { FALSE } \\
\text { NEGATIVE }\end{array}$ & $\begin{array}{l}\text { FALSE } \\
\text { POSITIVE }\end{array}$ \\
\hline TUMORS & $\begin{array}{l}12 \\
7 \text { - squamous } \\
3 \text { - small-cell } \\
1 \text { - ca. larynges } \\
\text { WLB-negative } \\
1 \text { - squamous. } \\
\text { (CIS) synchronous } \\
\text { - WLB-negative }\end{array}$ & $\begin{array}{l}17 \\
9 \text { - normal } \\
7 \text { - non-specific } \\
\text { inflammation } \\
1 \text { - metaplasia }\end{array}$ & $\begin{array}{l}2 \\
1 \text { - small-cell } \\
1 \text { - squamous } \\
\text { both WLB-positive }\end{array}$ & $\begin{array}{l}7 \\
4 \text { - normal } \\
1 \text { - non-specific } \\
\text { inflammation } \\
2 \text { - metaplasia }\end{array}$ \\
\hline $\begin{array}{l}\text { RESECTED } \\
\text { LUNG TUMORS }\end{array}$ & $\begin{array}{l}1 \\
\text { squamous } \\
\text { recurrent - } \\
\text { WLB-negative }\end{array}$ & $\begin{array}{l}1 \\
\text { non-specific } \\
\text { inflammation }\end{array}$ & 0 & 0 \\
\hline POST-LARYNGECTOMY & $\begin{array}{l}1 \\
\text { severe dysplasia } \\
\text { WLB-negative }\end{array}$ & $\begin{array}{l}3 \\
\text { normal }\end{array}$ & $\begin{array}{l}1 \\
\text { moderate dysplasia } \\
\text { WLB-negative }\end{array}$ & $\begin{array}{l}3 \\
2 \text { - normal } \\
1 \text { - non-specific } \\
\text { inflammation }\end{array}$ \\
\hline HEAVY SMOKERS & 0 & $\begin{array}{l}7 \\
4 \text { - normal } \\
3 \text { - non-specific } \\
\text { inflammation }\end{array}$ & 0 & $\begin{array}{l}7 \\
1 \text { - metaplasia } \\
5 \text { - non-specific } \\
\text { inflammation } \\
1 \text { - normal }\end{array}$ \\
\hline $\begin{array}{l}\text { TOTAL } \\
5 \text { ml ALA }\end{array}$ & $9(22.5 \%)$ & $18(42.5 \%)$ & $3(7.5 \%)$ & $11(27.5 \%)$ \\
\hline $\begin{array}{l}\text { TOTAL } \\
10 \mathrm{ml} \text { ALA }\end{array}$ & $5(23 \%)$ & $11(50 \%)$ & 0 & $6(27 \%)$ \\
\hline TOTAL 5+10 ml ALA & $14(23 \%)$ & $28(45 \%)$ & $3(5 \%)$ & $17(27 \%)$ \\
\hline
\end{tabular}


Table 3. - A summary of PDD positive and PDD negative findings compared with pathological results for all patients

\begin{tabular}{lcccc}
\hline & \multicolumn{2}{c}{ PDD (+) } & \multicolumn{2}{c}{ PDD (-) } \\
\cline { 2 - 5 } & $n$ & $\%$ & $n$ & $\%$ \\
\hline Invasive carcinoma & 12 & 38 & 2 & 6 \\
CIS & 1 & 3 & 0 & 0 \\
Dysplasia & 1 & 3 & 1 & 3 \\
Metaplasia & 3 & 9 & 1 & 3 \\
Non-specific inflammation & 8 & 25 & 11 & 34 \\
Normal & 7 & 22 & 17 & 53 \\
\hline
\end{tabular}

over, the analysis was done separately for patients who received 5 and $10 \mathrm{ml}$ 5-ALA;

2. Present or past history of respiratory neoplasms - only patients with present or past history of respiratory neoplasm, all lesions;

3. The same as 2 but without WLB-visible tumors - detection of synchronous/metachronous lesions;

4. Only early lesions in all groups (WLB-visible tumors excluded)

The results are presented in table 4 .

In the group of patients with tumours there were: 7 intraluminal tumours (5 squamous, 2 smallcell carcinomas); 5 concentric infiltrates/intramural growth (2 squamous, 1 NSCLC, 2 small-cell); and 5 extrabronchial tumours (not visible in bronchoscopy, detected on X-ray/CT, histopathological examination not available). Patients with tumors growing outside the bronchi were not treated as visible tumours and were only included in the analysis of safety, and occurrence of early synchronous lesions. Table 5 shows the distribution of fluorescence in the group of patients with advanced tumours.

The distribution of true positive, true negative, false positive and false negative values was similar in groups of patients who inhaled 5 and $10 \mathrm{ml}$ of 5 ALA (not significant).

Among true positive results four were classified as WLB-negative (laryngeal carcinoma, CIS synchronous, squamous recurrence in a stump, severe dysplasia) and among false negatives two were WLB-positive (1 squamous, 1 small cell) and one WLB-negative (moderate dysplasia). The values of sensitivity, specificity, PPV and NPV for WLB and WLB combined with ALA-enhanced fluorescent bronchoscopy (WLB+ALA) were also compared for the whole study population. WLB+ALA increased sensitivity by $2.1 \%$ (from 91.6 to 93.8) and NPV by 6\% (from 90.9 to 96.9), but decreased specificity by $35.4 \%$ (from 100 to 64.6) and PPV by $53.1 \%$ (from 100 to 46.9). The same results in a group of past or present tumours (group 2) were as follows: sensitivity increased by $22 \%$ (from 72 to 94 , relative sensitivity - 1.31), NPV by $34 \%$ (from 62 to 96 ) but specificity decreased by $26 \%$ (from 100 to 74) and PPV by 35 $\%$ (from 100 to 65 ).

Safety evaluations. Two patients from those who received $5 \mathrm{ml}$ of 5-ALA $(5.7 \%)$ and one from the group who received $10 \mathrm{ml}(7.1 \%)$ reported mild cough during the inhalation. None of examined patients reported dyspnea, wheezing, expectoration or any other respiratory symptom. The incidence of adverse symptoms for all patients was $6.1 \%$. There were no statistically significant differences in pre- and post-inhalation $\mathrm{FEV}_{1}$ between groups of patients inhaling 5 and $10 \mathrm{ml} 5$-ALA. Pre- vs. post-inhalatory values were $2.20 \pm 0.98$ vs. $2.20 \pm 0.98$ (not significant) and $2.14 \pm 0.99$ vs. $2.02 \pm 0.93$ (not significant) for 5 and $10 \mathrm{ml}$, respectively. None of the patients who inhaled $5 \mathrm{ml}$ of 5-ALA had significant decrease of $\mathrm{FEV}_{1}$. In 4 of them $\mathrm{FEV}_{1}$ increased above $200 \mathrm{ml}$ and more than $10 \%$. Two patients who received $10 \mathrm{ml} 5$ ALA presented a significant drop in $\mathrm{FEV}_{1}(760 \mathrm{ml}$ - 29\% and $370 \mathrm{ml}-13 \%$ ). None of these patients reported cough, dyspnea, or other respiratory

Table 4. - Sensitivity, specificity, positive predictive value (PPV) and negative predictive value (NPV) in various sub-groups. Group 1 includes all examined patients and all lesions (both WLB- visible and not visible). Subgroups $1 \mathrm{~A}$ and $1 \mathrm{~B}$ show values for patients who inhaled 5 and $10 \mathrm{ml} 5$-ALA, separately. Group 2 includes only patients with present and past history of respiratory, smoking-related neoplasms, including WLB-visible and invisible lesions. Group 3 includes the same patients as group 2, but WLB-visible lesions were excluded. Group 4 has been formed for estimation of PDD detective value of early pre-neoplastic/neoplastic lesions; this group includes patients from all groups but without WLB-visible lesions

$\begin{array}{ccc}\text { GROUP 1 } & \mathbf{1 A} & \mathbf{1 B} \\ \text { all patients } & 5 \mathrm{ml} & 10 \mathrm{ml} \\ \text { \& lesions } & 5 \text {-ALA } & 5-\text { ALA }\end{array}$

GROUP 2
past and
present
respiratory
neoplasms,
all lesions

GROUP 3
past and
present
respiratory
neoplasms
but without
WLB-visible
lesions

GROUP 4

all patients but WLBvisible lesions excluded

WLB-visible

esions

\begin{tabular}{lllllll}
\hline sensitivity & 82 & 75 & 100 & 82 & 75 & 75 \\
specificity & 62 & 62 & 65 & 68 & 55 & 53 \\
PPV & 45 & 45 & 45 & 58 & 23 & 15 \\
NPV & 90 & 86 & 100 & 88 & 92 & 95 \\
\hline
\end{tabular}




\begin{tabular}{|c|c|c|}
\hline & PDD & PATHOLOGY \\
\hline \multirow[t]{2}{*}{ INTRALUMINAL } & PDD (+) - 6 & $\begin{array}{l}4 \text { - squamous } \\
2 \text { - small-cell }\end{array}$ \\
\hline & $\operatorname{PDD}(-)-1$ & squamous \\
\hline \multirow[t]{2}{*}{ INTRAMURAL } & PDD (+) - 4 & $\begin{array}{l}2 \text { - squamous } \\
1 \text { - NSCLC } \\
1 \text { - small-cell }\end{array}$ \\
\hline & PDD (-) - 1 & small-cell \\
\hline \multirow[t]{2}{*}{ EXTRA-BRONCHIAL } & $\operatorname{PDD}(+)-0$ & undefined \\
\hline & PDD (-) - 5 & \\
\hline LARYNGEAL & PDD (+) & squamous \\
\hline
\end{tabular}

symptom. Both originated from the heavy smokers group, the first one did not show pre-inhalation ventilatory disturbances, and the second had borderline pre-inhalation spirometry $\left(\mathrm{FEV}_{1}-80 \%\right.$ of predicted, $\left.\mathrm{FEV}_{1} \% \mathrm{FVC}-72 \%\right)$. In both patients bronchial obstruction provoked by 5-ALA inhalation was reversible after inhalation of short-acting $\beta$-agonist. In the second patient, the reversibility test performed a week later showed also a positive response to $200 \mu \mathrm{g}$ of salbutamol (increase of $\mathrm{FEV}_{1}>12 \%$ and $>200 \mathrm{ml}$ ). Figure 1 shows $\mathrm{FEV}_{1}$ values before and after 5-ALA inhalation. There was no skin toxicity within a 4-week follow-up period.

\section{Discussion}

The medical diagnostic procedure should be reliable, safe, convenient (both for a patient and a doctor) and inexpensive. Conventional white light bronchoscopy is a routine diagnostic procedure, available widely. Although its role in the modern pneumology is commonly recognized, it has, unfortunately, some limitations. One such limitation is the possibility of overlooking early neoplastic changes. Fluorescent bronchoscopy offers a chance to improve the detection of early malignant lesions. There are only few reports on the validation of fluorescence bronchoscopy, the majority based on autoflourescence. In a British Columbia Cancer Agency Lung Health Study 511 heavy current or ex-smokers (>30 pack-years) were examined by autofluorescence bronchoscopy (lung imaging fluorescence endoscope [LIFE] - Xillix Technologies Corp.) [2]. In fluorescence-positive pathological samples 5\% were normal, 30\% evaluated hyperplasia and metaplasia, $44 \%$ mild dysplasia, $13 \%$ moderate dysplasia, 6\% severe dysplasia, $1.6 \%$ CIS and $0.4 \%$ invasive carcinoma. The meta-analysis which included results from few different studies and centres (about 1500 patients) showed sensitivity ranging from 71 to $81 \%$, specificity from 57 to $71 \%$, PPV from 25 to $47 \%$ and NPV from 92 to $95 \%$ [9]. Our results remain within these limits, when visible tumors are included in the analysis. When we exclude obvious tumours, specificity and PPV fall dawn. It is due to high percentage of normal results and other non malignant changes in PDD positive samples. The best results are reached when heavy smokers without obvious respiratory neoplasms are excluded (group 2). The comparison of WLB vs. WLB+ALA is also taken into consideration. In this group the relative sensitivity was 1.31 . In the present study heavy smokers had a minimum cigarette consumption of 20 pack-years (mean consumption 31 packyears) and were qualified for the bronchoscopy because of cough or a change of its character, episodes of hemoptysis, or some doubts considering chest-Xray. When we consider the mean cigarette consumption above 40 pack-years in patients with present or past history of tumors and possible predisposition to neoplastic disease, we can state that the total risk in the group of smokers without signs of respiratory neoplasm is relatively low. In a cited study [2], as well as in many others the aut-

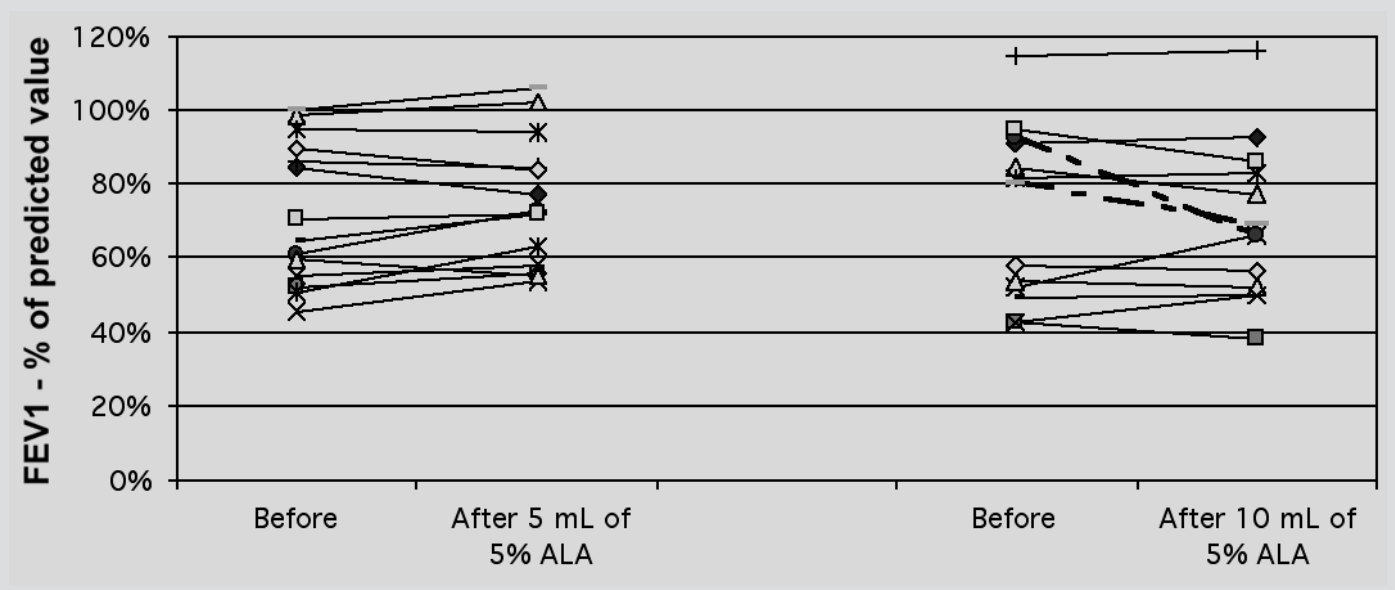

Fig. 1. $-\mathrm{FEV}_{1}$ presented as $\%$ of predicted value before and after 5-ALA inhalation: $5 \mathrm{ml}$ - left column; $10 \mathrm{ml}$ - right column. An intermittent bolded line shows cases with a significant drop in $\mathrm{FEV}_{1}$ (more than $10 \%$ of initial value). 
ofluorescence system was used (LIFE, Xillix). The literature on the use of Storz D-light system in detection of bronchial malignancies is less abundant. In all available studies on PDD performed with Storz D-light system the photosensitisers have been used (mainly 5-ALA). On the other hand all studies performed with Xillix system were based on autofluorescence. In addition, studies comparing both systems are not available. Neither of these systems have been evaluated in terms of the possible superiority of photosensitiser-enhanced fluorescence over autofluorescence. In view of the above we presume, that the comparison of results obtained by autoflorescence (Xillix) and ALA-enhanced PDD (Storz) only on the basis of available literature is a misuse. The present authors have some experience obtained on a small group of patients with obvious bronchial tumours, who had first autofluorescent PDD and few days later ALA-enhanced PDD. Although the group is too small to provide any statistical results, we are convinced about the superiority of ALA-enhanced PDD over autofluorescence in case of Storz D-light system (see figure $5 \mathrm{~A}, \mathrm{~B}$ and $\mathrm{C}$ ). There is no doubt, that this problem deserves separate studies on a higher number of patients. Another possible advantage of the application of photosensitisers is the possibility to irradiate the sensibilized lesions by a non-thermal low energy laser (PDT), although the usefulness of inhaled ALA for this indication must be also verified separately.
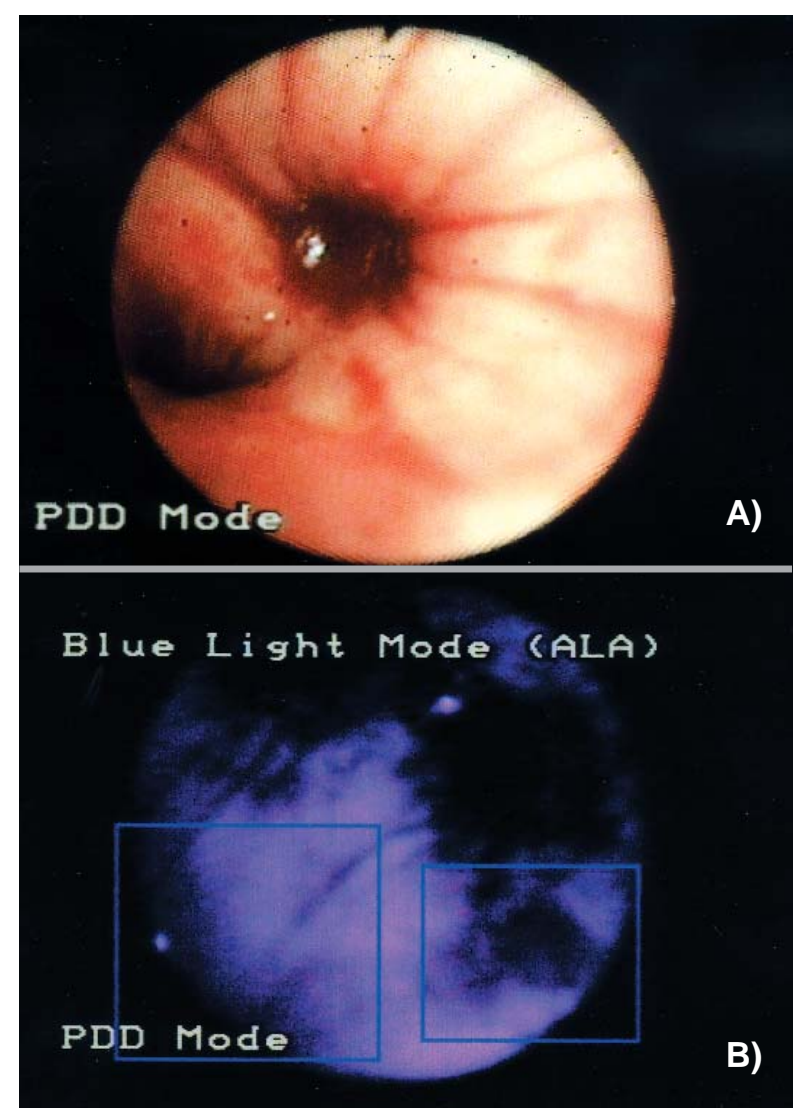

Fig. 2. - A squamous cell carcinoma infiltrating intermediate bronchus in white light (A) and PDD-mode (B) - purple illumination marked by blue frame
We believe, that high percentage of false positive results is related to detection of small hemorrhagic foci in mucosa. These changes look slightly differently in violet light, are darker and the focus is usually visible in white-light imagination. On the other hand such small hemorrhagic foci may reflect early neoplastic transformation. Therefore we have treated all such lesions as PDD positive samples.

In our material we found one recurrent squamous cell carcinoma in a patient 5 years after lobectomy, in whom the lesion was not evident in white light, and one synchronous lesion on the opposite site (CIS) in a patient with a tumour occluding lower lobe bronchus. We also detected a PDDpositive but doubtful in white light infiltration in the upper larynx in a patient subjected to bronchoscopy due to hemoptysis (squamous carcinoma). All these lesions were treated as WLB-negative. There was also one PDD-positive and WLBnegative focus of severe dysplasia and one PDD/WLB-negative focus of moderate dysplasia (false negative).

We found, that the centre of a large tumour growing into the lumen of a bronchus often presents in a violet light as PDD negative. It is probably related to the presence of a superficial necrosis. However, PDD positive area is usually seen in a tumour periphery (figure 2 and 3 ). Our results also confirmed what had been already published by other authors, that tumours forming submucosal infiltrates are difficult to visualize [2]. The
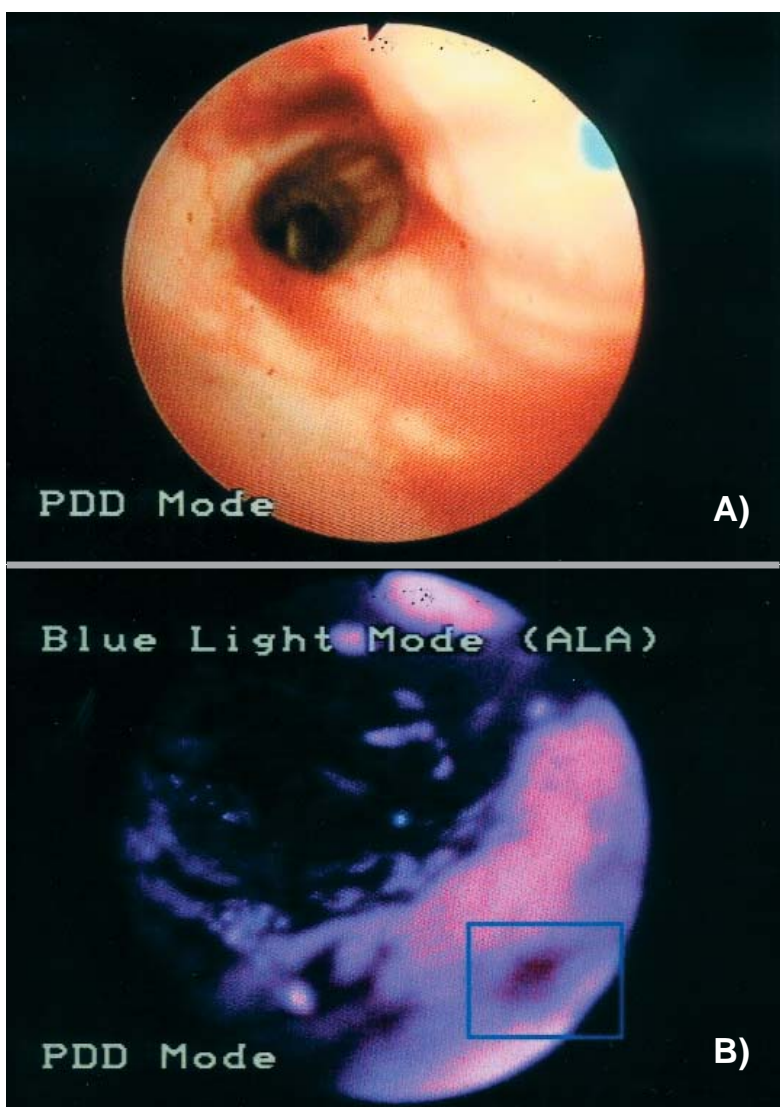

Fig. 3. - A squamous-cell carcinoma with intramural growth in a main bronchus in white-light (A) and PDD-mode (B) - purple illumination marked by blue frame. 


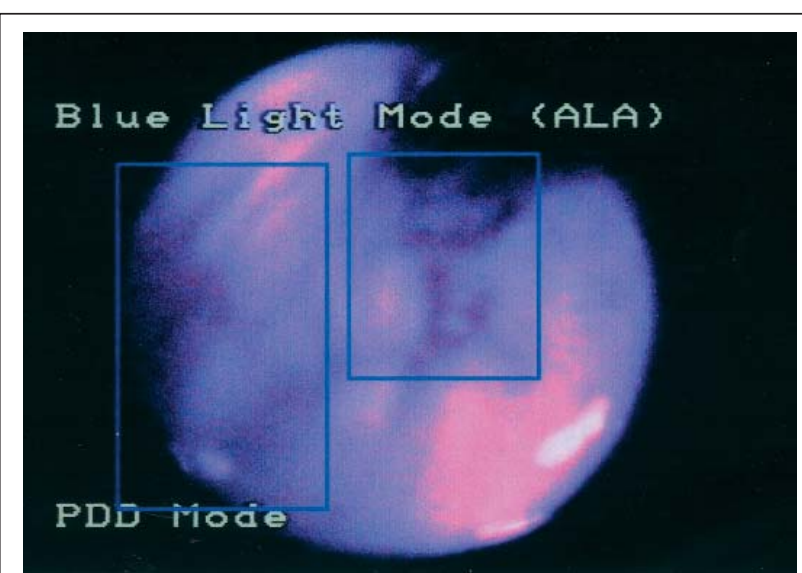

Fig. 4. - A synchronous foci on the opposite site in the same patient as shown on figure 3. PDD-mode - purple illumination marked by blue frame.

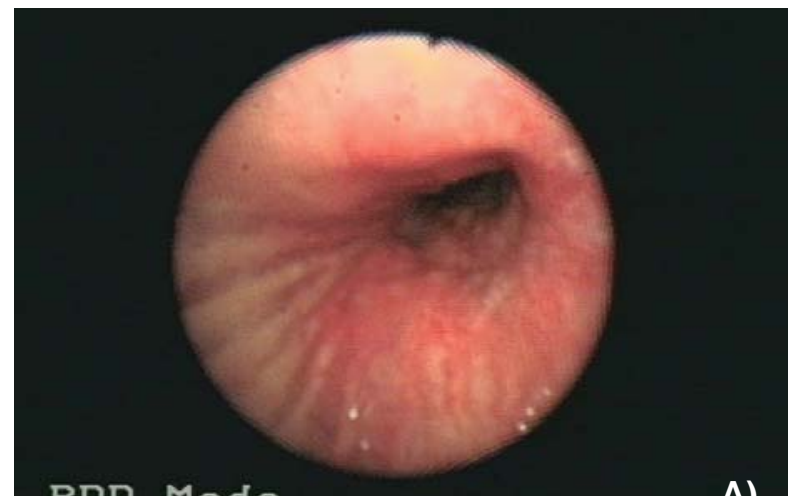

PDD Mode
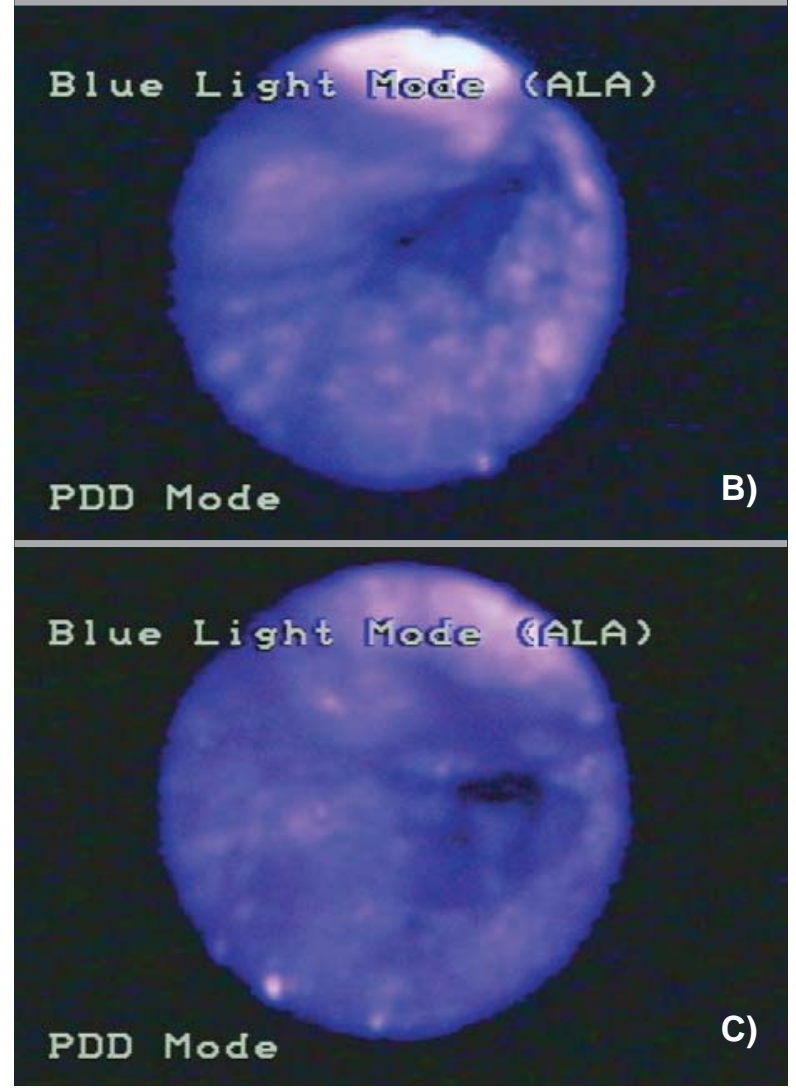

Fig. 5. - Intramural growth of squamous cell carcinoma: A - white light bronchoscopy; B - autofluorescence by Storz D-light; C - PDD after 5-ALA inhalation. The area of dark-red fluorescence is more extensive in ALA-PDD than in autofluorescence bronchoscopy. "easiest" for photodynamic detection are superficially growing tumours (most often sqamous cell carcinoma). In a study of Pierard [10] $60 \%$ of neoplasms detected by autofluorescence were squamous cell carcinomas, whereas $40 \%$ were adenocarcionomas. This is also a case in our study, where 7 out of 11 PDD positive biopsies revealed squamous cell type of pathology and 1 was diagnosed as non-small cell lung cancer (NSCLC). In our material we also found 3 smallcell PDD positive carcinomas (none in the material of Pierard), but the difference is probably related to an advanced stage of tumors in our group. In five cases of extrabronchial tumours we have not found any changes neither in white-light nor in fluorescence bronchoscopy, what means that PDD is useless in the diagnosis of extra-bronchial tumours (most of such tumours are small cell carcinomas).

One of our goals was to estimate a safety of 5ALA inhalations. In order to choose the most convenient dose we have changed between 5 and $10 \mathrm{ml}$. Although it was not a randomised experiment but rather a change in the protocol done during the study, we compared the sensitivity, specificity, PPV and NPV for 5 and $10 \mathrm{ml}$ subgroups. Although there were no statistically significant differences, a trend towards higher sensitivity and NPV values was observed in a $10 \mathrm{ml}$ group. Although there were no respiratory symptoms and changes in physical examination caused by 5ALA inhalation even in patients with severe underlying pathology (COPD), in two cases we found a significant drop in $\mathrm{FEV}_{1}$. It happened only in a group receiving higher dose of the stain. This fall in FEV 1 probably reflects bronchial constriction in patients with underlying bronchial hyperreactivity (both were heavy smokers, one was treated with anti-asthmatic drugs for COPD and the reversibility test taken a week later was positive, the other denied a history of episodes of shortness of breath). It is caused either by acidic $\mathrm{pH}$ or high osmolality (or both). This finding indicates, that special care should be taken in patients with a history of asthma or COPD. Bronchodilators should be available. Salbutamol or ipratropium bromide could be added to 5-ALA solution to prevent a bronchospasm. As the time of inhalation may be important (in case of $10 \mathrm{ml}$ it lasted up to 60 minutes), the inhalation could be applied in two stages divided by, for instance, a 30 minutes break.

Routinely, 5-ALA is used orally in a dose of 60 $\mathrm{mg} / \mathrm{kg}$ body weight, what gives $3.6 \mathrm{~g}$ for $60 \mathrm{~kg}$, whereas inhalation of $10 \mathrm{ml}$ is equivalent to $0.5 \mathrm{~g}$. It gives approximately 7-times cost reduction. It is the cheapest commercially available stain. Other stains (HpD) are significantly more expensive. Moreover, as no skin toxicity was observed, precautions regarding protection against sunlight is not necessary, and may allow for further cost reduction.

In conclusion, although a high percentage of false positive results reported in our study seems to be a common feature of fluorescent bronchoscopy 
in general, photodynamic diagnosis with 5-ALA inhalations, due to above mentioned disadvantage, should not be recommended as a screening tool. Results comparing autofluorescence with ALAenhanced fluorescent bronchoscopy are not available. Thus it is not possible to draw conclusions on the possible superiority of ALA-PDD over autofluorescence. The results achieved in our study are comparable or even worse than autofluorescence by LIFE system. Despite these disadvantages it should not be neglected, that the combination of WLB and ALA-PDD is superior to WLB alone and that ALA-enhanced PDD shows high sensitivity and NPV, thus the risk of overlooking a neoplastic lesion is decreased. In this context we believe, that PDD after ALA inhalations may be a good guide for a bronchoscopist where to take a biopsy from. It may be especially useful for detection of early malignant changes in patients prepared for surgery due to lung cancer (synchronous lesions and good recognition of infiltration margins) and in patients operated due to lung tumour in the past (metachronous lesions and stump control). Another possible application of ALA inhalations could be photodynamic therapy (instead of general application), however this needs to be proved in practice.

The method is safe, however special care should be taken in patients at risk from bronchial constriction. As it is not always possible to indicate those patients on the basis of history, physical examination or pre-inhalation spirometry, the operating team should be always prepared for such medical situation.

\section{References}

1. Kennedy CK, Miller Y, Prindville S. Screening for lung cancer revisited and the role of sputum cytology and fluorescence bronchoscopy in a high-risk group. Chest 2000; 117: 72S-9S.

2. Lam S, Kennedy T, Unger M, et al. Localization of bronchial intraepithelial neoplastic lesions by fluorescence bronchoscopy. Chest 1998; 113: 696-702.

3. Lipinski M, Jeromin L. Comparison of the bladder tumour antigen test with photodynamic diagnosis in patients with pathologically confirmed recurrent superficial urinary bladder tumours. BJU Int 2002; 89: 757-9.

4. Ceylan C, Erboz S, Ozdenir F, Alper S. Topical photodynamic therapy for intraepithelial epithelioma. $J$ Eur Acad Dermatol Venereol 2002; 16: 292-4.

5. Mehlmann M, Betz CS, Stepp H, et al. Fluorescence staining of laryngeal neoplasms after topical application of 5-Aminolevulinic Acid: Preliminary Results. Lasers Med Surg 1999; 25: 414-20.

6. Leunig A, Mehlmann M, Betz C, et al. Fluorescence staining of oral cancer using a topical application of 5aminolevulinic acid: fluorescence microscopic studies. J Photochem Photobiol B 2001; 60: 44-9.

7. Baumgartner R, Huber RM, Schulz H, et al. Inhalation of 5-aminolevulinic acid: a new technique for fluorescence detection of early stage lung cancer. J Photochem Photobiol B 1996; 36: 169-74.

8. British Thoracic Society Bronchoscopy Guidelines Committee, A subcommittee of the Standards of Care Committee of the British Thoracic Society. Thorax 2001; 56 (suppl I): i1-i21.

9. Lam S, MacAulay C, leRiche JC, Palic B. Detection and localization of early lung cancer by fluorescence bronchoscopy. Cancer Supplement 2000; 89: 2468-73.

10. Pierard P, Vermylen P, Bosschaerts T, et al. Synchronous rentgenographically occult lung carcinoma in patients with resectable primary lung cancer. Chest 2000; 117: 779-85.

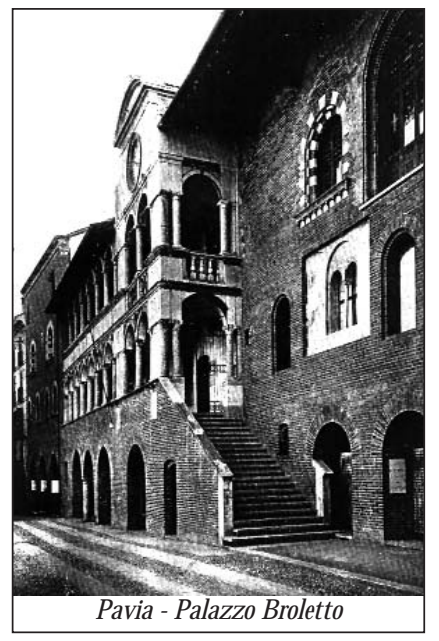

